\title{
Qualitative Research Methods in Mental Health
}

Sarah Peters

Evid Based Mental Health 2010 13: 35-40

doi: 10.1136/ebmh.13.2.35

Updated information and services can be found at:

http://ebmh.bmj.com/content/13/2/35.full.html

These include:

References This article cites 30 articles, 9 of which can be accessed free at: http://ebmh.bmj.com/content/13/2/35.full.htmI\#ref-list-1

Email alerting Receive free email alerts when new articles cite this article. Sign up in the service box at the top right corner of the online article.

Notes

To order reprints of this article go to:

http://ebmh.bmj.com/cgi/reprintform

To subscribe to Evidence Based Mental Health go to:

http://ebmh.bmj.com/subscriptions 


\section{Qualitative Research Methods in Mental Health}

\section{Dr Sarah Peters}

As the evidence base for the study of mental health problems develops, there is a need for increasingly rigorous and systematic research methodologies. Complex questions require complex methodological approaches. Recognising this, the MRC guidelines for developing and testing complex interventions place qualitative methods as integral to each stage of intervention development and implementation. However, mental health research has lagged behind many other healthcare specialities in using qualitative methods within its evidence base. Rigour in qualitative research raises many similar issues to quantitative research and also some additional challenges. This article examines the role of qualitative methods within mental heath research, describes key methodological and analytical approaches and offers guidance on how to differentiate between poor and good quality qualitative research.

\section{THE TRAJECTORY OF QUALITATIVE METHODS IN MENTAL HEALTH RESEARCH}

Qualitative methodologies have a clear home within the study of mental health research. Early and, arguably, seminal work into the study of mental illnesses and their management was based on detailed observation, moving towards theory using inductive reasoning. Case studies have been long established in psychiatry to present detailed analysis of unusual cases or novel treatments. Participant observation was the principle method used in Goffman's seminal study of psychiatric patients in asylums that informed his ideas about the institutionalising and medicalising of mental illness by medical practice. ${ }^{1}$ However, the 20 th century saw the 'behaviourist revolution', a movement where quantification and experimentation dominated. Researchers sought to identify cause and effects, and reasoning became more deductive - seeking to use data to confirm theory. The study of health and illness was determined by contemporary thinking about disease, taking

Correspondence to: Dr Sarah Peters, School of Psychological Sciences, The University of Manchester, Coupland Building 1, Oxford Road M13 9PL, UK; sarah.peters@manchester.ac.uk a biomedical stance. Psychologists and clinical health researchers exploited natural science methodologies, attempting to measure phenomenon in their smallest entities and do so as objectively as possible. This reductionist and positivist philosophy shaped advances in research methods and meant that qualitative exploration failed to develop as a credible scientific approach. Indeed, 'objectivity' and the 'discovery of truth' have become synonymous with 'scientific enquiry' and qualitative methods are easily dismissed as 'anecdotal'. The underlying epistemology of this approach chimes well with medical practice for which training is predominately in laboratory and basic sciences (such as physics and chemistry) within which the discourse of natural laws dominate. To this end, research in psychiatry still remains overwhelmingly quantitative. $^{2}$

Underlying all research paradigms are assumptions. However, most traditional researchers remain unaware of these until they start to use alternative paradigms. Key assumptions of quantitative research are that facts exist that can be quantified and measured and that these should be examined, as far as possible, objectively, partialling out or controlling for the context within which they exist. There are research questions within mental health where this approach can hold: where phenomenon of interest can be reliably and meaningfully quantified and measured, it is feasible to use data to test predictions and examine change. However, for many questions these assumptions prove unsatisfying. It is often not possible or desirable to try and create laboratory conditions for the research; indeed it would be ecologically invalid to do so. For example, to understand the experience of an individual who has been newly diagnosed with schizophrenia, it is clearly important to consider the context within which they live, their family, social grouping and media messages they are exposed to. Table 1 depicts the key differences between the two methodological approaches and core underlying assumptions for each.

It should be cautioned that it is easy to fall into the trap of categorising studies as either quantitative or qualitative. The two traditions are often positioned within the literature as opposing and in conflict. This division is unhelpful and likely to impede methodological advancement. Though, undeniably, there are differences in the two approaches to research, there are also many exceptions that expose this dichotomy to be simplistic: some qualitative studies seek to test a priori hypotheses, and some quantitative studies are atheoretical and exploratory. ${ }^{3}$ Hence it is more useful to consider research methodologies as lying along a spectrum and that researchers should be familiar with the full range of methodologies, so that a method is chosen according to the research question rather than the researcher's ability.

\section{RATIONALE FOR QUALITATIVE METHODS IN CURRENT MENTAL HEALTH RESEARCH}

There are a number of scientific, practical and ethical reasons why mental health is an area that can particularly benefit from qualitative enquiry. Mental health research is complex. Health problems are multifactorial in their aetiology and the consequences they have on the individual, families and societies. Management can involve self-help, pharmacological, educative, social and psychotherapeutic approaches. Services involved are often multidisciplinary and require liaison between a number of individuals including professionals, service-users and relatives. Many problems are exacerbated by poor treatment compliance and lack of access to, or engagement with, appropriate services. ${ }^{4}$

Engagement with mental health research can also be challenging. Topics may be highly sensitive or private. Individuals may have impaired capacity or be at high risk. During the research process there may be revelations of suicidal ideation or criminal activity. Hence mental health research can raise additional ethical issues. In other cases scepticism of services makes for reluctant research participants. However, if we accept the case that meaningful research can be based in subjective enquiry then qualitative methods provide a way of giving voice to participants. Qualitative methods offer an effective way of involving service-users in developing interventions for mental health problems ${ }^{5}$ ensuring that the questions asked are meaningful to individuals. This may be particularly beneficial if participants are stakeholders, for example potential users of a new service. 
Table 1 Comparison of underlying assumptions of quantitative and qualitative research approaches

\begin{tabular}{|c|c|c|}
\hline & Quantitative & Qualitative \\
\hline Approach towards data & Objective. Data and its interpretation is, as far as possible, value free. & Subjective. Researcher interpretation is a feature of the analysis. \\
\hline $\begin{array}{l}\text { Theoretical framework } \\
\text { employed }\end{array}$ & $\begin{array}{l}\text { Positivism and reductionism. Proposes that there are universal 'truths' } \\
\text { that scientific enquiry can uncover. } \\
\text { Research seeks to identify the smallest measurable entities to further } \\
\text { knowledge about how entities relate to each other. }\end{array}$ & $\begin{array}{l}\text { Social constructivism or realism. Proposes that all knowledge } \\
\text { (including science) is constructed by groups and hence there is no single } \\
\text { reality or truth. }\end{array}$ \\
\hline Context of study & Artificial settings. Researcher attempts to control for confounding factors. & Natural settings. Researcher recognises and examines context and bias. \\
\hline Sampling & $\begin{array}{l}\text { Statistical for example random, consecutive. Attempts to minimise bias in } \\
\text { final sample so it will represent the population from which it is drawn. } \\
\text { Statistical methods can be used to pre-determine the sample size needed } \\
\text { for analytical power. }\end{array}$ & $\begin{array}{l}\text { Theoretical for example purposive. Attempts to seek full range of } \\
\text { existing views, including those that are deviant or atypical. Theoretical } \\
\text { stance taken to determine whether data (and thereby sample size) is } \\
\text { sufficient to enable analysis to be complete. Saturation is achieved when } \\
\text { no new categories emerge from data. }\end{array}$ \\
\hline Data generation & $\begin{array}{l}\text { Numerical. Gathered using questionnaires, surveys, quantification of } \\
\text { behaviours or events. Data are simple and involve many participants. }\end{array}$ & $\begin{array}{l}\text { Non numerical. Generated through interviews, observation of naturally } \\
\text { occurring phenomenon, focus groups, document analysis. Data are rich } \\
\text { and involve few participants. }\end{array}$ \\
\hline Analysis approach & $\begin{array}{l}\text { Deductive, i.e. theory driven. Findings are confirmatory and test } \\
\text { pre-existing hypotheses and theory }\end{array}$ & $\begin{array}{l}\text { Inductive, i.e. data driven. Findings are exploratory and form hypotheses } \\
\text { and theory }\end{array}$ \\
\hline Reporting & Findings supported by evidence of numerical data and statistical analyses & Findings supported by evidence of textual, pictorial or narrative data \\
\hline
\end{tabular}

Qualitative methods are valuable for individuals who have limited literacy skills who struggle with pencil and paper measures. For example qualitative research has proved fruitful in understanding children's concepts of mental illness and associated services. ${ }^{6}$

\section{HOW QUALITATIVE ENQUIRY IS USED WITHIN MENTAL HEALTH RESEARCH}

There are a range of types of research question where qualitative methods prove useful - from the development and testing of theory, to the piloting and establishing efficacy of treatment approaches, to understanding issues around translation and implementation into routine practice. Each is discussed in turn.

\section{Development and testing of theory}

Qualitative methods are important in exploratory work and in generating understanding of a phenomenon, stimulating new ideas or building new theory. For example, stigma is a concept that is recognised as a barrier to accessing services and also an added burden to mental health. A focus-group study sought to understand the meaning of stigma from the perspectives of individuals with schizophrenia, their relatives and health professionals. ${ }^{7}$ From this they developed a four-dimensional theory which has subsequently informed interventions to reduce stigma and discrimination that target not only engagement with psychiatric services but also interactions with the public and work.?

\section{Development of tools and measures}

Qualitative methods access personal accounts, capturing how individuals talk about a lived experience. This can be invaluable for designing new research tools. For example, Mavaddat and colleagues used focus groups with 56 patients with severe or common mental health problems to explore their experiences of primary care management. ${ }^{8}$ Nine focus groups were conducted and analysis identified key themes. From these, items were generated to form a Patient Experience Questionnaire, of which the psychometric properties were subsequently examined quantitatively in a larger sample. Not only can dimensions be identified, the rich qualitative data provide terminology that is meaningful to service users that can then be incorporated into question items.

\section{Development and testing of interventions}

As we have seen, qualitative methods can inform the development of new interventions. The gold-standard methodology for investigating treatment effectiveness is the randomised controlled trial (RCT), with the principle output being an effect size or demonstration that the primary outcome was significantly improved for participants in the intervention arm compared with those in the control/ comparison arm. Nevertheless, what will be familiar for researchers and clinicians involved in trials is that immense research and clinical learning arises from these substantial, often lengthy and expensive research endeavours. Qualitative methods provide a means to empirically capture these lessons, whether they are about recruitment, therapy training/ supervision, treatment delivery or content. These data are essential to improve the feasibility and acceptability of further trials and developing the intervention. Conducting qualitative work prior to embarking on an RCT can inform the design, delivery and recruitment, as well as engage relevant stakeholders early in the process; all of these can prevent costly errors. Qualitative research can also be used during a trial to identify reasons for poor recruitment: in one RCT, implementing findings from this type of investigation led to an increased randomisation rate from $40 \%$ to $70 \% .^{9}$

Nesting qualitative research within a trial can be viewed as taking out an insurance policy as data are generated which can later help explain negative or surprising findings. A recent trial of reattribution training for GPs to manage medically unexplained symptoms demonstrated substantial improvements in GP consultation behaviour. ${ }^{10}$ However, effects on clinical outcomes were counterintuitive. A series of nested qualitative studies helped shed light as to why this was the case: patients' illness models were complex, and they resisted engaging with GPs (who they perceived as having more simplistic and dualistic understanding) because they were anxious it would lead to non-identification or misdiagnosis of any potential future disease ${ }^{11}$, an issue that can be addressed in future interventions. Even if the insights are unsurprising to those involved in the research, the data collected have been generated systematically and can be subjected to peer review and disseminated. For this reason, there is an increasing expectation from funding bodies that qualitative methodologies are integral to psychosocial intervention research.

\section{Translation and implementation into clinical practice}

Trials provide limited information about how treatments can be implemented into clinical practice or applied to another 
context. Psychological interventions are more effective when delivered within trial settings by experts involved in their development than when they are delivered within clinical settings. ${ }^{12}$ Qualitative methods can help us understand how to implement research findings into routine practice. $^{13}$

Understanding what stakeholders value about a service and what barriers exist to its uptake is another evidence base to inform clinicians' practice. Relapse prevention is an effective psychoeducation approach that helps individuals with bipolar disorder extend time to relapse. Qualitative methodologies identified which aspects of the intervention service-users and care-coordinators value, and hence, are likely to utilise in routine care. ${ }^{14}$ The intervention facilitated better understanding of bipolar disorder (by both parties), demonstrating, in turn, a rationale for medication. Patients discovered new, empowering and less socially isolated ways of managing their symptoms, which had important impacts on interactions with healthcare staff and family members. Furthermore, care-coordinators' reported how they used elements of the intervention when working with clients with other diagnoses. The research also provided insights as to where difficulties may occur when implementing a particular intervention into routine care. For example, for carecoordinators this proved a novel way of working with clients that was more emotionally demanding, thus highlighting the need for supervision and managerial support. ${ }^{14}$

\section{BEGINNERS GUIDE TO QUALITATIVE APPROACHES: ONE SIZE DOESN'T FIT} ALL

Just as there is a range of quantitative research designs and statistical analyses to choose from, so there are many types of qualitative methods. Choosing a method can be daunting to an inexperienced or beginner-level qualitative researcher, for it requires engaging with new terms and ways of thinking about knowledge. The following summary sets out analytic and data-generation approaches that are used commonly in mental health research. It is not intended to be comprehensive and is provided only as a point of access/ familiarisation to researchers less familiar with the literature.

\section{Data generation}

Qualitative data are generated in several ways. Most commonly, researchers seek a sample and conduct a series of individual in-depth interviews, seeking participants' views on topics of interest. Typically these last upwards of $45 \mathrm{~min}$ and are organised on the basis of a schedule of topics identified from the literature or pilot work. This does not act as a questionnaire, however; rather, it acts as a flexible framework for exploring areas of interest. The researcher combines open questions to elicit free responses, with focused questions for probing and prompting participants to provide effective responses. Usually interviews are audio-recorded and transcribed verbatim for subsequent analysis.

As interviews are held in privately, and on one-to-one basis, they provide scope to develop a trusting relationship so that participants are comfortable disclosing socially undesirable views. For example, in a study of practice nurses views of chronic fatigue syndrome, some nurses described patients as lazy or illegitimate - a view that challenges the stereotype of a nursing professional as a sympathetic and caring person. ${ }^{15}$ This gives important information about the education and supervision required to enable or train general nurses to ensure that they are capable of delivering psychological interventions for these types of problems.

Alternatively, groups of participants are brought together for a focus group, which usually lasts for 2 hours. Although it is tempting to consider focus groups as an efficient way of acquiring data from several participants simultaneously, there are disadvantages. They are difficult to organise for geographically dispersed or busy participants, and there are compromises to confidentiality, particularly within 'captive' populations (eg, within an organisation individuals may be unwilling to criticise). Group dynamics must be considered; the presence of a dominant or self-professed expert can inhibit the group and, therefore, prevent useful data generation. When the subject mater is sensitive, individuals may be unwilling to discuss experiences in a group, although it often promotes a shared experience that can be empowering. Most of these problems are avoided by careful planning of the group composition and ensuring the group is conducted by a highly skilled facilitator. Lester and colleagues ${ }^{16}$ used focus-group sessions with patients and health professionals to understand the experience of dealing with serious mental illness. Though initially participants were observed via focus-group sessions that used patient-only and health professional only groups, subsequently on combined focus groups were used that contained both patients and health professionals. ${ }^{16}$ The primary advantage of focus groups is that they enable generation of data about how individuals discuss and interact about a phenomenon; thus, a well-conducted focus group can be an extremely rich source of data.

A different type of data are naturally occurring dialogue and behaviours. These may be recorded through observation and detailed field notes (see ethnography in Table 2) or analysed from audio/ video-recordings. Other data sources include texts, for example, diaries, clinical notes, Internet blogs and so on. Qualitative data can even be generated through postal surveys. We thematically analysed responses to an open-ended question set within a survey about medical educators' views of behavioural and social sciences (BSS). ${ }^{17}$ From this, key barriers to integrating BSS within medical training were identified, which included an entrenched biomedical mindset. The themes were analysed in relation to existing literature and revealed that despite radical changes in medical training, the power of the hidden curriculum persists. ${ }^{17}$

\section{ANALYSING QUALITATIVE DATA}

Researchers bring a wide range of analytical approaches to the data. A comprehensive and detailed discussion of the philosophy underlying different methods is beyond the scope of this paper; however, a summary of the key analytical approaches used in mental health research are provided in Table 2. An illustrative example is provided for each approach to offer some insight into the commonalities and differences between methodologies. The procedure for analysis for all methods involves successive stages of data familiarisation/immersion, followed by seeking and reviewing patterns within the data, which may then be defined and categorized as specific themes. Researchers move back and forth between data generation and analysis, confirming or disconfirming emerging ideas. The relationship of the analysis to theory-testing or theorybuilding depends on the methodology used.

Some approaches are more common in healthcare than others. Interpretative phenomenological (IPA) analysis and thematic analysis have proved particularly popular. In contrast, ethnographic research requires a high level of researcher investment and reflexivity and can prove challenging for NHS ethic committees. Consequently, it remains under used in healthcare research. 
Table 2 Key features of a range of analytical approaches used within mental health research

\begin{tabular}{|c|c|c|}
\hline Analytical approach & Key features & Illustration from the literature \\
\hline Content analysis & $\begin{array}{l}\text { Organises data according to pre-defined categories. } \\
\text { May include quantifying of categories, or participants in different } \\
\text { categories, and hence can be considered a form of quantitative } \\
\text { research. } \\
\text { Inter-rater reliability analyses can be performed. }\end{array}$ & $\begin{array}{l}220 \text { min of the popular reality TV series The Osbournes was } \\
\text { used to determine the quantity, source and slant of verbal and visual } \\
\text { messages relating to substance use. Depictions were common with } \\
\text { alcohol and tobacco messages being primarily endorsements and drug } \\
\text { depictions primarily rejections. Rejections were presented verbally and } \\
\text { endorsements presented visually. }{ }^{21}\end{array}$ \\
\hline Framework analysis ${ }^{22}$ & $\begin{array}{l}\text { Data are organised using pre-determined ideas within charts, } \\
\text { although analysis is inductive. } \\
\text { Analysis is quick to conduct but can lack depth. } \\
\text { Used principally within social policy research. }\end{array}$ & $\begin{array}{l}\text { Analysis of interviews and focus groups with } 106 \text { mental health } \\
\text { stakeholders in Uganda. A reciprocal relationship between mental health } \\
\text { and poverty was recognised and stigma for each reinforced problems. } \\
\text { The findings supported a policy in stigma reduction programmes to } \\
\text { protect mentally ill within deprived communities. }{ }^{23}\end{array}$ \\
\hline Thematic analysis ${ }^{24}$ & $\begin{array}{l}\text { Researcher seeks patterns in the data. } \\
\text { Data usually gathered during semi-structured interviews or focus } \\
\text { groups. } \\
\text { Can use pre-existing theoretical framework to approach the data. }\end{array}$ & $\begin{array}{l}\text { Interviews conducted with } 22 \text { consultant psychiatrists to examine } \\
\text { decision-making about prescribing antipsychotic medications. Personally } \\
\text { acquired knowledge was found to be more instrumental than clinical } \\
\text { guidelines in making prescribing decisions. }{ }^{25}\end{array}$ \\
\hline Grounded theory ${ }^{28}$ & $\begin{array}{l}\text { Seeks to develop new theory inductively from data. Analysis is } \\
\text { guided accordingly. } \\
\text { Data usually gathered during semi-structured interviews or focus } \\
\text { groups. } \\
\text { Constant comparative technique used to generate data to test and } \\
\text { inform the theory under development. }\end{array}$ & $\begin{array}{l}\text { Secondary qualitative analysis of a series of qualitative studies was } \\
\text { used to build new theory (Normalisation Process Model) to explain } \\
\text { the integration of complex innovations into routine clinical practice. } \\
\text { The theory proposes four mechanisms of the work individuals } \\
\text { and organisations undertake to achieve this (coherence, cognitive } \\
\text { participation, collective action and reflexive monitoring). }{ }^{13}\end{array}$ \\
\hline Discourse analysis ${ }^{29}$ & $\begin{array}{l}\text { Involves micro and macro-analysis of naturally occurring segments } \\
\text { within exchanges. } \\
\text { Seeks to examine the fundamental patterns that function behind } \\
\text { language including conversation (talk-in-interaction) and texts. } \\
\text { Common forms of discourse analysis include sociolinguistics and } \\
\text { conversational analysis. }\end{array}$ & $\begin{array}{l}\text { Analysis of consultations between psychiatrists and patients at a gender } \\
\text { identity clinic. Findings reveal the diagnostic function of psychiatrists' } \\
\text { use of hypothetical questions to test patients' commitment to their } \\
\text { aspired-for gender role. }{ }^{30}\end{array}$ \\
\hline Meta-synthesis ${ }^{33}$ & $\begin{array}{l}\text { Seeks to systematically summarise findings from a group of similar } \\
\text { studies. } \\
\text { Studies are identified for inclusion using the same literature searching } \\
\text { principles as for quantitative systematic reviews. } \\
\text { Findings are weighted according to the quality of the evidence. } \\
\text { Concepts and themes reported in individual studies are subjected to } \\
\text { qualitative analysis and methodological needs within the literature } \\
\text { identified. }\end{array}$ & $\begin{array}{l}\text { Findings from } 24 \text { qualitative studies of patients' perception of Anorexia } \\
\text { Nervosa were synthesised. It was found that patients interpret the } \\
\text { illness as part of their identity and control. The authors identified } \\
\text { limitations in the literature, including poor study quality and a lack of male } \\
\text { participants. }^{34}\end{array}$ \\
\hline
\end{tabular}

For each a key reference for further reading is listed.

\section{Recruitment and sampling}

Quantitative research is interested in identifying the typical, or average. By contrast, qualitative research aims to discover and examine the breadth of views held within a community. This includes extreme or deviant views and views that are absent. Consequently, qualitative researchers do not necessarily (though in some circumstances they may) seek to identify a representative sample. Instead, the aim may be to sample across the range of views. Hence, qualitative research can comment on what views exist and what this means, but it is not possible to infer the proportions of people from the wider population that hold a particular view.

However, sampling for a qualitative study is not any less systematic or considered. In a quantitative study one would take a statistical approach to sampling, for example, selecting a random sample or recruiting consecutive referrals, or every 10th out-patient attendee. Qualitative studies, instead, often elect to use theoretical means to identify a sample. This is often purposive; that is, the researcher uses theoretical principles to choose the attributes of included participants. Healey and colleagues conducted a study to understand the reasons for individuals with bipolar disorder misusing substances. ${ }^{18}$ They sought to include participants who were current users of each substance group, and the recruitment strategy evolved to actively target specific cases.

Qualitative studies typically use far smaller samples than quantitative studies. The number varies depending on the richness of the data yielded and the type of analytic approach that can range from a single case to more than 100 participants. 
As with all research, it is unethical to recruit more participants than needed to address the question at hand; a qualitative sample should be sufficient for thematic saturation to be achieved from the data.

\section{Ensuring that findings are valid and generalisable}

A common question from individuals new to qualitative research is how can findings from a study of few participants be generalised to the wider population? In some circumstances, findings from an individual study (quantitative or qualitative) may have limited generalisability; therefore, more studies may need to be conducted, in order to build local knowledge that can then be tested or explored across similar groups. ${ }^{4}$ However, all qualitative studies should create new insights that have theoretical or clinical relevance which enables the study to extend understanding beyond the individual participants and to the wider population. In some cases, this can lead to generation of new theory (see grounded theory in Table 2).

Reliability and validity are two important ways of ascertaining rigor in quantitative research. Qualitative research seeks to understand individual construction and, by definition, is subjective. It is unlikely, therefore, that a study could ever be repeated with exactly the same circumstances. Instead, qualitative research is concerned with the question of whether the findings are trustworthy; that is, if the same circumstances were to prevail, would the same conclusions would be drawn?

There are a number of ways to maximise trustworthiness. One is triangulation, of which there are three subtypes. Data triangulation involves using data from several sources (eg, interviews, documentation, observation). A research team may include members from different backgrounds (eg, psychology, psychiatry, sociology), enabling a range of perspectives to be used within the discussion and interpretation of the data. This is termed researcher triangulation. The final subtype, theoretical triangulation, requires using more than one theory to examine the research question. Another technique to establish the trustworthiness of the findings is to use respondent validation. Here, the final or interim analysis is presented to members of the population of interest to ascertain whether interpretations made are valid.

An important aspect of all qualitative studies is researcher reflexivity. Here researchers consider their role and how their experience and knowledge might influence the generation, analysis and interpretation of the data. As with all well-conducted research, a clear record of progress should be kept - to enable scrutiny of recruitment, data generation and development of analysis. However, transparency is particularly important in qualitative research as the concepts and views evolve and are refined during the process.

\section{JUDGING QUALITY IN QUALITATIVE RESEARCH}

Within all fields of research there are better and worse ways of conducting a study, and range of quality in mental health qualitative research is variable. Many of the principles for judging quality in qualitative research are the same for judging quality in any other type of research. However, several guidelines have been developed to help readers,

\section{Box 1 Guidelines for authors and reviewers of qualitative research (adapted from Malterud ${ }^{35}$ )}

Aim

- Is the research question relevant and clearly stated?

\section{Reflexivity}

- Are the researcher's motives and background presented?

Method, sampling and data collection

- Is a qualitative method appropriate and justified?

- Is the sampling strategy clearly described and justified?

- Is the method for data generation fully described

- Are the characteristics of the sample sufficiently described?

Theoretical framework

- Was a theoretical framework used and stated?

Analysis

- Are the principles and procedures for data organisation and analysis described and justified?

- Are strategies used to test the trustworthiness of the findings?

\section{Findings}

- Are the findings relevant to the aim of the study?

- Are data (e.g. quotes) used to support and enrich the findings?

- Are the conclusions directly linked to the study? Are you convinced?

- Do the findings have clinical or theoretical value?

\section{Discussion}

- Are findings compared to appropriate theoretical and empirical literature?

- Are questions about the internal and external validity and reflexivity discussed?

- Are shortcomings of the design, and the implications these have on findings, examined?

- Are clinical/theoretical implications of the findings made?

\section{Presentation}

- Is the report understandable and clearly contextualised?

- Is it possible to distinguish between the voices of informants and researchers?

- Are sources from the field used and appropriately referenced? 
of treatments and how best to support clinicians and service users in managing mental health problems. An important development in the field is how to integrate methodological approaches to address questions. This raises a number of challenges, such as how to integrate textual and numerical data and how to reconcile different epistemologies. A distinction can be made between mixedmethod design (eg, quantitative and qualitative data are gathered and findings combined within a single or series of studies) and mixed-model study, a pragmatist approach, whereby aspects of qualitative and quantitative research are combined at different stages during a research process. ${ }^{19}$ Qualitative research is still often viewed as only a support function or as secondary to quantitative research; however, this situation is likely to evolve as more researchers gain a broader skill set.

Though it is undeniable that there has been a marked increase in the volume and quality of qualitative research published within the past two decades, mental health research has been surprisingly slow to develop, compared to other disciplines e.g. general practice and nursing, with relatively fewer qualitative research findings reaching mainstream psychiatric journals. ${ }^{2}$ This does not appear to reflect overall editorial policy; however, it may be partly due to the lack of confidence on the part of editors and reviewers while identifying rigorous qualitative research data for further publication. ${ }^{20}$ However, the skilled researcher should no longer find him or herself forced into a position of defending a single-methodology camp (quantitative vs qualitative), but should be equipped with the necessary methodological and analytical skills to study and interpret data and to appraise and interpret others' findings from a full range of methodological techniques.

\section{REFERENCES}

1. Goffman E. Asylums: essays on the social situation of mental patients and other inmates. New York: Doubleday; 1961 .
2. Crawford MJ, Ghosh P, Keen R. Use of qualitative research methods in general medicine and psychiatry: publication trends in medical journals 1990-2000. Int J Soc Psychiatry 2003;49:308-11.

3. McBeth $\mathbf{J}$, Cordingley L. Current issues and new direction in psychology and health: epidemiology and health psychology-please bridge the gap. Psychol Health 2009;24:861-5.

4. Dowrick C, Gask L, Edwards S, et al.; AMP Group. Researching the mental health needs of hardto-reach groups: managing multiple sources of evidence. BMC Health Serv Res 2009;9:226.

5. MRC Developing and Evaluating Complex Interventions 2008

6. Nelson ML, Quintana SM. Qualitative clinical research with children and adolescents. J Clin Child Adolesc Psychol 2005;34:344-56.

7. Schulze B, Angermeyer MC. Subjective experiences of stigma. A focus group study of schizophrenic patients, their relatives and mental health professionals. Soc Sci Med 2003;56:299-312.

8. Mavaddat N, Lester HE, Tait L. Development of a patient experience questionnaire for primary care mental health. Qual Saf Health Care 2009;18:147-52.

9. Donovan J, Mills N, Smith M, et al. Quality improvement report: Improving design and conduct of randomised trials by embedding them in qualitative research: Protec $T$ (prostate testing for cancer and treatment) study. Commentary: presenting unbiased information to patients can be difficult. $B M J$ 2002;325:766-70.

10. Morriss R, Dowrick C, Salmon P, et al. Cluster randomised controlled trial of training practices in reattribution for medically unexplained symptoms. Br J Psychiatry 2007;191:536-42.

11. Peters S, Rogers A, Salmon P, et al. What do patients choose to tell their doctors? Qualitative analysis of potential barriers to reattributing medically unexplained symptoms. J Gen Intern Med 2009;24:443-9.

12. Barkham M, Stiles WB, Connell J, et al. Effects of psychological therapies in randomized trials and practice-based studies. Br J Clin Psychol 2008;47(Pt 4):397-415.

13. May C, Finch T. Implementing, embedding, and integrating practices: an outline of normalization process theory. Sociology 2009;43:535-54.

14. Pontin E, Peters S, Lobban F, et al. Enhanced relapse prevention for bipolar disorder: a qualitative investigation of value perceived for service users and care coordinators. Implement Sci 2009;4:4.

15. Chew-Graham C, Dixon R, Shaw JW, et al. Practice Nurses' views of their role in the management of Chronic Fatigue Syndrome/Myalagic Encephalitis: a qualitative study. BMC Nurs 2009;8:2.

16. Lester H, Tait L, England E, et al. Patient involvement in primary care mental health: a focus group study. Br J Gen Pract 2006;56:415-22.

17. Litva A, Peters $S$. Exploring barriers to teaching behavioural and social sciences in medical education. Med Educ 2008;42:309-14.
18. Healey C, Peters S, Kinderman P, et al. Reasons for substance use in dual diagnosis bipolar disorder and substance use disorders: a qualitative study. J Affect Disord 2009;113:118-26.

19. Tashakkoria A, Teddlie C. Mixed methodology: combining qualitative and quantitative approaches. Thousand Oaks:Sage; 1998.

20. Kidd SA. The role of qualitative research in psychological journals. Psychol Methods 2002; 7:126-38.

21. Blair NA, Yue SK, Singh R, et al. Depictions of substance use in reality television: a content analysis of The Osbournes. BMJ 2005;331:1517-9.

22. Ritchie J, Spencer L. Qualitative data analysis for applied policy research. In Bryman A, Burgess $\mathrm{R}$ (eds) Analyzing qualitative research. London: Routledge;1994;173-94.

23. Ssebunnya J, Kigozi F, Lund C, et al. Stakeholder perceptions of mental health stigma and poverty in Uganda. BMC Int Health Hum Rights 2009;9:5.

24. Braun V, Clarke V. Using thematic analysis in psychology. Oua Res Psychol 2006;3:77-101.

25. Barley M, Pope C, Chilvers R, Sipos A, Harrison G. Guidelines or mindlines? A qualitative study exploring what knowledge informs psychiatrists decisions about antipsychotic prescribing. J Ment Health 2008;17:9-17.

26. Smith JA. Beyond the divide between cognition and discourse: Using interpretative phenomenological analysis in health psychology. Psychol Health 1996;11:261-271.

27. Glasman D, Finlay WM, Brock D. Becoming a self-therapist: using cognitive-behavioural therapy for recurrent depression and/or dysthymia after completing therapy. Psychol Psychother 2004;77(Pt 3):335-51.

28. Strauss A, Corbin J. Basics of qualitative research: techniques and procedures for developing grounded theory. Thousand Oaks:Sage; 1998.

29. Hodges BD, Kuper A, Reeves S. Discourse analysis. BMJ 2008;337:a879.

30. Speer SA, Parsons C. Gatekeeping gender: some features of the use of hypothetical questions in the psychiatric assessment of transsexual patients. Discourse Society 2006;17:785-812.

31. Reeves S, Kuper A, Hodges BD. Qualitative research methodologies: ethnography. BMJ 2008;337:a1020.

32. Dobransky K. The good, the bad, and the severely mentally ill: Official and informal labels as organizational resources in community mental health services. Soc Sci Med 2009;69:722-8.

33. Dixon-Woods $\mathbf{M}$, Fitzpatrick R, Roberts K. Including qualitative research in systematic reviews: opportunities and problems. J Eval Clin Pract 2001; 7:125-33.

34. Espíndola CR, Blay SL. Anorexia nervosa's meaning to patients: a qualitative synthesis. Psychopathology 2009;42:69-80.

35. Malterud K. Qualitative research: standards, challenges, and guidelines. Lancet 2001;358:483-8. 